\title{
Analysis of Determinants of Late First Antenatal Care (ANC) Booking in Kasenengwa District, Eastern Province, Zambia: A Cross-Sectional Study
}

\author{
Siamondole Mike Wachata ${ }^{1,2, ~ *, ~ G o d f r e y ~ L i n g e n d a ~}{ }^{1}$, Eustarckio Kazonga ${ }^{1}$ \\ ${ }^{1}$ Department of Public Health, School of Medicine and Health Sciences, University of Lusaka, Lusaka, Zambia \\ ${ }^{2}$ Department of Public Health, Kasenengwa District Health Office, Kasenengwa, Zambia
}

Email address:

siamondolemike@yahoo.com (S. M. Wachata)

${ }^{*}$ Corresponding author

\section{To cite this article:}

Siamondole Mike Wachata, Godfrey Lingenda, Eustarckio Kazonga. Analysis of Determinants of Late First Antenatal Care (ANC) Booking in Kasenengwa District, Eastern Province, Zambia: A Cross-Sectional Study. Journal of Gynecology and Obstetrics.

Vol. 9, No. 5, 2021, pp. 178-188. doi: 10.11648/j.jgo.20210905.18

Received: September 15, 2021; Accepted: October 11, 2021; Published: October 30, 2021

\begin{abstract}
Antenatal care (ANC) is an important public health screening tool to promote better outcomes in pregnant women and their unborn children. Women who book for ANC early enjoy the benefits of early detection of any probable condition which can affect the pregnant woman or her fetus. The objective of the study was to analyse determinants of late First ANC booking among pregnant women in Kasenegwa district in the Eastern Province of Zambia. The study design was a cross-sectional focusing on first ANC women, which used a multi-stage sampling design to sample the health facilities included in the study. Purposive and simple random sampling methods were used to come up with the sample size of 225 pregnant women. Logistic regression was used to analyse the data using Statistical Package for Social Sciences (SPSS) Version 20. The prevalence of late ANC booking was $53 \%(107 / 118)$ in the study area. The binary logistic regression analysis revealed that maternal age (OR=1.7 $\mathrm{p}$-value $=<0.0001)$, Marital status $(\mathrm{OR}=7.6,95 \% \mathrm{CI}=2.801-21.020, \mathrm{p}$-value $=<0.0001)$, Education $(\mathrm{OR}=6.9, \mathrm{p}$-value $=0.030)$, Knowledge on the need to book early for ANC despite any noticeable complications (OR=7.964, 95\% CI $=2.308-27.486$, $\mathrm{p}$-value $=0.001)$, decision making to book for $\mathrm{ANC}(\mathrm{OR}=.111,95 \% \mathrm{CI}=.059-.208$, $\mathrm{p}$-value $=.000)$, maternal gravida $(\mathrm{OR}=1.47$, $\mathrm{p}$-value $=0.012)$, Parity $(\mathrm{OR}=1.65 \mathrm{p}$-value $=0.024)$, unplanned pregnancy $(\mathrm{OR}=2.1,95 \% \mathrm{CI}=6.385-71.406 \mathrm{p}$-value $=<0.0001)$, and staff attitude $(\mathrm{OR}=1.973,95 \% \mathrm{CI}=1.730-2.249$, $\mathrm{p}$-value $=0.006)$ were found to be significant determinants. From the results, it can be deduced that Late ANC booking is high in Kasenengwa District and factors associated with this problem are maternal age, maternal marital status, maternal gravida/parity, spouse/husband nonsupport and pregnancy uncertainty.
\end{abstract}

Keywords: Antenatal Care Booking, Maternal Health, Pregnancy, First Trimester, Kasenengwa

\section{Introduction}

Antenatal care (ANC) refers to the attention provided to pregnant women and pubescent girls by skilled health personnel. Appropriate care is provided to ensure that both the mother and baby have the best health conditions during pregnancy [1]. Therefore, ANC is a screening tool to avert adverse outcomes in pregnant women and their children. The World Health Organisation (WHO) ANC guidelines specify that during ANC, pregnant women are empowered with information and education, assessed and screened for the purpose of identifying any pregnancy related risks and diseases [1]. It is during ANC that pre-existing complications, complications that develop due to unhealthy living conditions and actual pregnancy complications are identified [2]. Pregnant women are further physically and psychologically prepared for delivery and motherhood. ANC is, therefore, a vital tool for decreasing pregnancy related impediments including maternal mortality rate [3]. The WHO recommends that pregnant women should get in contact with the health system the moment they become aware they are pregnant preferably within the first trimester of their pregnancy. Despite the benefits that come with early ANC booking, most pregnant women in sub-Saharan Africa and Zambia in particular, still 
book for ANC late. This puts the pregnant women at risk of maternal deaths. Therefore, the purpose of this study is to analyse determinants of late first ANC booking among pregnant women in Kasenegwa district in Zambia.

\subsection{Statement of the Problem}

The WHO recommends that pregnant women have the first contact with the health system for ANC at 8-12 weeks of their pregnancy in the first trimester. This has been an accepted international standard [4]. First ANC booking is a significant component of ANC. It is used as a preliminary basis on which subsequent visit decisions will be based. Therefore, early booking helps to effectively monitor the health of the mother and fetus based on the correct timing of the subsequent visits advised by the trained health personnel [5]. Additionally, it promotes early detection of any abnormalities such as abnormal Blood Pressure. Women who book early for ANC are provided with necessary information and education for the preparation of safe motherhood and their blood is tested early for Human Immunodeficiency Virus (HIV), Syphilis and Hemoglobin which promote subsequent assessments and monitoring [6]. Despite the aforementioned benefits of early ANC booking, women mainly in sub-Saharan Africa delay booking for ANC. Most of them have their first antenatal booking in their second or third trimester of the pregnancy [7]. According to the Zambia Demographic and Health Survey (ZDHS), only $37 \%$ of women had their first antenatal visit in the first trimester of pregnancy [8]. The analysis of data from 3,979 women aged 15 to 49 years indicated that only $19 \%$ pregnant women had booked for ANC before 14 weeks of gestation [9]. Kasenengwa District, where this research was conducted reported $19.5 \%, 14.7 \%, 20.2 \%$ and $21.9 \%$ in the years 2015, 2016, 2017, and 2018 of ANC booking before 14 weeks respectively [10].

\subsection{Objectives}

\subsubsection{General Objectives}

To analyse determinants of late first ANC booking in Kasenengwa district.

\subsubsection{Specific Objectives}

The following were the specific objectives for the study:

i. To assess the relationship between women's factors and late first ANC booking.

ii. To explore the relationship between societal and traditional factors with late first ANC booking.

iii. To determine the relationship between health systems factors and late first ANC booking.

\subsection{Research Questions}

i. What is the relationship between women's factors with late first ANC booking?

ii. What is the relationship between societal and traditional factors with late first ANC booking?

iii. What is the relationship between health systems factors and late first ANC booking?

\section{Literature Review}

\subsection{Early ANC Booking}

Early ANC booking varies from place to place and amongst different countries. Some countries tend to do better than the others. Equally some regions tend to do better than others.

\subsubsection{Early ANC Booking Globally}

There is a $43 \%$ increase on global ANC coverage beginning in the first trimester of pregnancy. This increase was recorded between 1990 and 2013. Hence, setting ANC booking in the first trimester at 58.6\% [11]. Different countries and regions have contributed differently to the increase. Latin American and Caribbean countries seem to be doing quite well on early ANC booking. In Colombia $76.1 \%$ of the pregnant women booked early for ANC but in Haiti $54.4 \%$ of pregnant women booked for ANC in their first trimester of the pregnancy. However, Asian countries seem to be significantly affected with late ANC booking. For example, in Nepal, $44.0 \%$ of the women booked for ANC in their first trimester. This figure clearly indicates a problem of late ANC booking in Nepal. Indonesia, however, seems to be doing well in early ANC booking at $78.9 \%$ [11]. The global picture of early ANC booking shows significant variation of early ANC booking among different continents and countries.

\subsubsection{Early ANC Booking in Africa}

Among the regions of Africa, West Africa has illustrated an increase in early ANC booking. At least eight of ten countries have indicated increase in early ANC booking. However, a decline has been recorded in Southern and Eastern Africa. Six of Eleven countries have experienced decline in early ANC booking [7]. For the sub-Sahara Africa, Demographic and Health Surveys indicate notable variation in ANC. For example, $14.9 \%$ of the women booked for ANC in their first trimester in Democratic Republic of Congo (DRC), 24.6\% for Nigeria and Rwanda recording 38.6\% of early ANC booking [11].

Among the countries not doing well in early ANC booking in the East African region is Ethiopia. According to Ethiopia Demographic and Health Survey [12], 11.2\% of women book for Antenatal care within 12 weeks of gestation in Ethiopia. Specific regions, however, have different contributions to the national statistics. Gondar town located in North West of Ethiopia is at $35.4 \%$ of early ANC booking [13]. Dilla Town of Ethiopia recorded a closer figure to Gondar with the town recording statistics of $35.4 \%$ of early ANC booking [13]. The capital city of the country, Addis Ababa, recorded late ANC booking of $59.8 \%$ [14]. Based on the reviewed African literature, it can be concluded that on comparative basis, sub-Saharan Africa region is highly affected with late ANC booking.

\subsubsection{Early ANC Booking in Zambia}

The Zambia Demographic and Health Survey recorded that $37 \%$ of women had their first ANC in their first trimester [8]. This indicates an increase of $13 \%$ from the recorded $24.4 \%$ of early booking in the previous survey. Despite this increase in 
early ANC booking, the country statistics are still below the national target on early ANC booking. Variations in statistics on ANC booking has been recorded according to different regions and districts within Zambia. According to the research results of [6], the prevalence of late ANC booking in Ndola and Mpongwe districts were $68.6 \%$ and $72 \%$ respectively. However, the research results of [15] indicate a drop in early ANC booking for Ndola district as the statistics indicated that only $13.44 \%$ booked for ANC within their first trimester of gestation. In Kasenengwa district where the study was conducted, $19.5 \%, 14.7 \%, 20.2 \%$ and $24 \%$ in the years 2015 , 2016, 2017 and 2018 of ANC booking before 14 weeks has been recorded respectively [10]. Variation is seen in the figures recorded in Kasenegwa district with the other districts and the National statistics. This variation can, therefore, be attributed to the difference in the factors that influence first ANC attendance.

\subsection{Determinants of Early ANC Booking}

Literature attributes different determinants of early ANC booking. These factors vary from one region to another. Globally, studies have discovered different factors affecting early ANC booking. Some studies have indicated a positive significant association between social economic status and early ANC booking. In London, women with higher economic status were more likely to begin ANC earlier than those with poor economic status [16]. A study in China indicates that financial constraint is a barrier to early ANC booking. Women of higher economic status are more likely to begin ANC early $[17,18]$. Studies have further indicated that utilisation of a particular health service is dependent on distance of accessing it. In Pakistan, a study discovered that access to obstetric care depends on availability of transport. It is further affected by distance covered from villages to the centre [19]. Likewise, in Nepal, distance is a significant factor affecting early ANC booking. Women covering longer distance to access health services were less likely to book early for ANC than their counterparts.

At the regional level, studies in Africa have indicated significant association between maternal age and early ANC booking similar to the global findings [20]. In Tanzania, the lower the maternal age the higher the likelihood of a pregnant woman to book early for ANC [23]. Furthermore, studies have indicated a significant association between maternal education, knowledge and attitude towards early ANC booking [23]. Women with higher education attainment are more likely to book early for ANC than those with lower education attainment [20].

Studies have further indicated a significant association between social economic factors and early ANC booking. A study conducted in Ethiopia indicated that the higher the economic status the higher the likelihood of early ANC booking [21]. In Ghana, social economic status of a woman was a significant factor to early ANC booking [22]. Furthermore, partner support was a significant social factor to early ANC booking. In Tanzania, women who were supported by partners during pregnancy were likely to book for ANC earlier by 3 weeks [23].

Obstetric factors such as maternal gravida and parity have been associated with early ANC booking. In Tanzania, parity is a significant factor that influences early ANC booking [23]. Similarly, in Ghana, higher parity women were less likely to book for ANC [24]. However, there has been mixed conclusions on the influence of religious factors on early ANC booking. Research conducted in in Ghana and Nigeria indicated no significant relationship between religious factors and early ANC booking [22].

\subsection{Determinants of Early ANC Booking in Zambia}

Different determinants are associated with early ANC booking in Zambia. Inadequate knowledge about ANC significantly affects early ANC booking [9]. Unwanted pregnancy is a further significant factor affecting early ANC booking according to [6]. Other studies have further discovered that women's perception on the benefits of ANC is a significant factor affecting early ANC booking. Research conducted in Mpongwe district of Copperbelt province indicated that women who perceived no benefits of early ANC booking were more likely to book late for ANC [6].

Different social factors in Zambia affect early ANC booking. These includes, privacy, community norms and beliefs. Lack of privacy significantly affects early ANC booking [6]. Community norms and cultural beliefs are other factors associated with late ANC booking. This in turn is influenced by cultural beliefs held by various women in respective communities [6]. Studies have indicated significant association between maternal age and early ANC in Zambia. In a study conducted by [15] in Ndola district of Copperbelt province, it was discovered that 25-29 and 40-44 aged pregnant women were less likely to book late for ANC compared to the teenage pregnant mothers. Furthermore, women aged 20-34 are more likely to book earlier for ANC than women younger than the age 20 years [9].

\subsection{Theoretical Framework}

The Andersen and Newman's Health Services Utilisation model was adopted as the appropriate theory for analysing determinants of low early ANC booking. Different factors can influence health seeking behaviors [18]. Andersen and Newman's health behavioral model discusses three major factors that can influence health seeking behavior. The three are predisposing factors, enabling factors and need factors [25].

\section{Methodology}

\subsection{Study Design}

This was an analytical cross-sectional study.

\subsection{Study Population}

All pregnant women who booked for first ANC in the public health institutions within Kasenengwa District. 
Estimate of the study population was based on monthly load of previous year of pregnant women who booked for first ANC at each health facility. The Health Management Information System [10] indicates that in the month of October 2018, the 8 Health Centres i.e. Kasenengwa, Kwenje, Kamlaza, Chiparamba, Samuel, Chiwoko, Madyimawe, and Chizenje recorded $32 \%, 36 \%, 32 \%, 27 \%, 40 \%, 31 \%, 33 \%$ and $34 \%$ of first ANC respectively. Furthermore, the 6 health posts in the same Month of October 2018 i.e. Katondo, Chinjala, Chipemmbele, Chikungu, Kadama, Kamboma, recorded 12\%, $16 \%, 10 \%, 15 \%, 13 \%$ and $11 \%$ of first ANC booking respectively. Total first ANC attendance in the Month of October from the Health Centre/Clinic and Health Post was
265 and 77 respectively. This gives a total of 342 as target population. Given this target population, health facilities servicing a population of less than 5000 are Health Posts. Health facilities servicing more than a population of 5000 are Rural Health Centres or Clinics.

\subsection{Study Site}

The study was conducted in Kasenengwa District, which shares its boarders with Chipangali, Chipata, Mambwe and Katete districts of Eastern Province in Zambia as demonstrated in Figure 1.

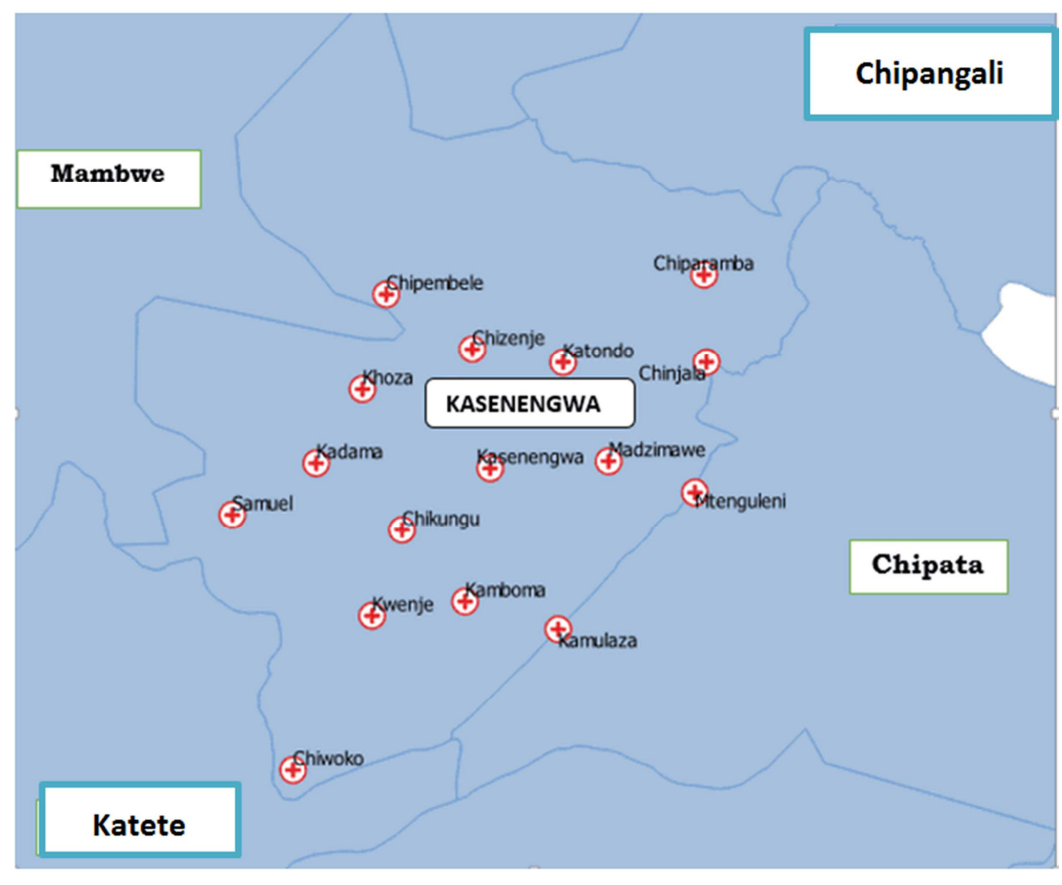

Source: Health Information management System [10].

Figure 1. Map of Kasenengwa District in Zambia.

\subsection{Sample Size}

In order to obtain the necessary sample sizes, Yamane formula [27] was used:

$$
\mathrm{n}=\frac{N}{1+N(e) 2}
$$

Where:

$\mathrm{n}=$ Sample Size

$\mathrm{N}=$ Population size

$\mathrm{e}=$ error margin $(0.05)$

Table 1. Sample Size Calculation.

\begin{tabular}{ll}
\hline From Health Post & From Health Centre/Clinic \\
\hline $\mathrm{n}=\frac{N}{1+N(e) 2}$ & $\mathrm{n}=\frac{N}{1+N(e) 2}$ \\
$\mathrm{n}=\frac{77}{1+77(0.05) 2}$ & $\mathrm{n}=\frac{265}{1+265(0.05) 2}$ \\
$\mathrm{n}=\frac{77}{1+77(0.0025)}$ & $\mathrm{n}=\frac{265}{1+265(0.0025)}$ \\
$\mathrm{n}=65$ & $\mathrm{n}=160$ \\
\hline
\end{tabular}

\subsection{Sampling Strategy}

Multi-stage sampling design was used to come up with the desired sample. The monthly load of previous year of pregnant women who booked for first ANC at each health facility was used as an estimate of the women who book for first ANC at each respective Health Centre/Clinic and Health Post in the month of data collection. An average of the sum of the monthly load per level of health care was used as a sample size per health facility.

\subsection{Data Collection}

Semi-structured questionnaires were used to collect data.

\subsection{Data Analysis}

Data was analysed using descriptive and inferential statistics. To determine the likelihoods between variables, Odds Ratios (ORs) were used in logistic regression analysis 
using Statistical Package for Social Sciences (SPSS) Version 20. The significance level used was $0.05(5 \%)$.

\subsection{Ethical Approval}

Ethical clearance was sought from the Health Research Ethics Committee of University of Lusaka and permission from Kasenengwa District Health Office (DHO). Ethical approval number was IORG0010092/MPH18112493. Participants were further at liberty to choose to participate or not in the research. Written informed consent was obtained from all individual participants. For the participants who consented, data collection tools were anonymised in order to ensure confidentiality of the information provided.

According to the Constitution of Zambia (Amendment) No. 2 of 2016, "child" means a person who has attained, or is below, the age of eighteen years. Based on this definition, all antenatal mothers in the age who had not attained the age of eighteen had consent forms completed by their parents.

\section{Results}

Table 2 presents the demographic characteristics of the participants. The majority $110(48.9 \%)$ of the participants were between $15-24$ years of age with the minority $18(8.0 \%)$ being 35-44 years of age. Age range of the participants was 15-44 years of age. The sampled participants were either married or single. Out of the 225 sampled, $195(86.7 \%)$ participants were married while $30(13 \%)$ were single. Majority of the participants $206(91.6 \%)$ were farmers. Teachers were $16(7.1 \%)$ with minority $3(1.3 \%)$ being nurses. Participants that had gone up to primary school level of education were $130(60.9 \%)$ and those that had not undergone any formal education were 28 (35.1\%). Those with secondary and tertiary levels of education were 67 (4\%). In terms of tribe, Chewas were the majority of the sampled population with a total number of $137(60.9 \%)$. Bemba were the minority $3(1.3 \%)$. Demographic characteristics are presented in Table 2 .

Table 2. Demographic Characteristics of Participants.

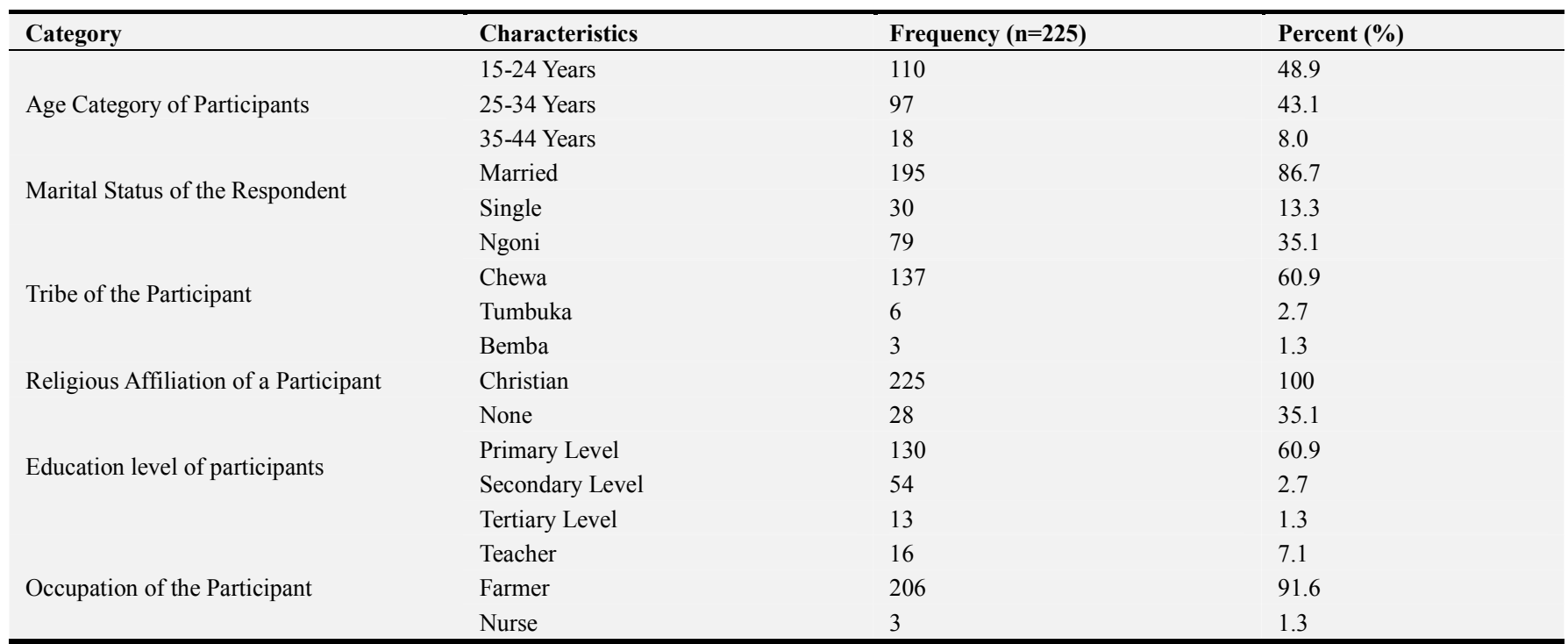

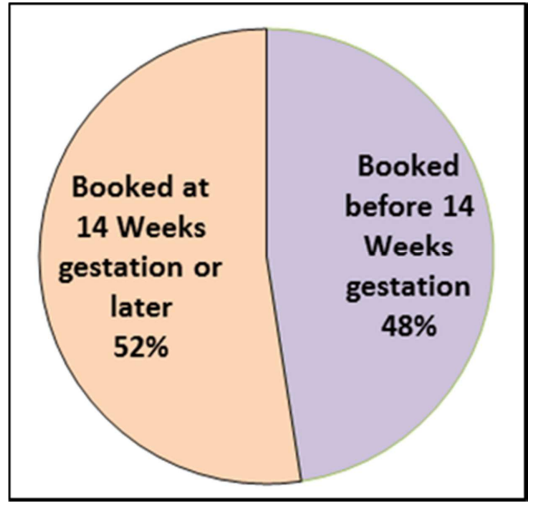

Figure 2. Gestation at $1^{\text {st }}$ ANC booking.

\subsection{Gestation at First ANC Booking}

Figure 2 shows that the majority of the participants booked at 14 weeks and after (52\%) with $48 \%$ booked before 14 weeks $(48 \%)$.

\subsection{Determinants of Late ANC Booking}

\subsubsection{Demographic Determinants of Late ANC Booking}

The logistic regression results in Table 3 indicate that there is a statistical significant relationship between early ANC booking and maternal age category $15-24$ years $(\mathrm{OR}=1.7$, $\mathrm{p}$-value $=0.00)$. Therefore, maternal age category of 15-24 years were 1.7 times more likely to book early for ANC than the other maternal ages. There is a further statistical significant relationship between early ANC booking and marital status of the participant $(\mathrm{OR}=7.6$, $\mathrm{p}$-value $=<0.0001)$. Single participants were 7.6 times more likely to book early for ANC than married participants. The test results further indicated a significant association between early ANC booking and maternal education i.e. Secondary school level $(\mathrm{OR}=6.9$, $\mathrm{p}$-value $=0.030)$, and Tertiary level $(\mathrm{OR}=1.964$, $\mathrm{p}$-value $=0.23)$. 
Table 3. Binary logistic regression for Demographic factors and Early ANC booking.

\begin{tabular}{|c|c|c|c|c|c|c|c|}
\hline \multirow{2}{*}{ Category } & \multirow{2}{*}{ Characteristic } & \multicolumn{2}{|c|}{ Gestation at the First ANC booking } & \multirow{2}{*}{ P-value } & \multirow{2}{*}{ OR } & \multicolumn{2}{|c|}{ 95.0\% C.I. for EXP $(\beta)$} \\
\hline & & Less than 14 Weeks & At 14 Weeks and Above & & & Lower & Upper \\
\hline \multirow{3}{*}{ Age } & 15-24 Years & $80(74.8)$ & $30(25.4)$ & .000 & 1.7 & 1.02 & 6.23 \\
\hline & 25-34 Years & $27(25.2)$ & $70(59.3)$ & .998 & .000 & .000 & .000 \\
\hline & 35-44 Years & $0(0)$ & $18(15.3)$ & .998 & .000 & .000 & .000 \\
\hline \multirow{3}{*}{$\begin{array}{l}\text { Marital Status of the } \\
\text { Respondent }\end{array}$} & Married & $95(88.8)$ & $100(84.7)$ & .000 & .584 & .254 & 1.346 \\
\hline & Single & $12(11.2)$ & $18(15.3)$ & .000 & 7.6 & 2.801 & 21.020 \\
\hline & Ngoni & $36(33.6)$ & $43(36.4)$ & .098 & .000 & .000 & .000 \\
\hline \multirow{4}{*}{$\begin{array}{l}\text { Tribe of the } \\
\text { Participant }\end{array}$} & Chewa & $68(63.6)$ & $69(58.5)$ & .999 & .000 & .000 & .000 \\
\hline & Tumbuka & $3(2.8)$ & $3(2.5)$ & .999 & .000 & .000 & .000 \\
\hline & Bemba & $0(0)$ & $3(2.5)$ & .999 & .000 & .000 & .000 \\
\hline & Non & $9(8.4)$ & $19(16.1)$ & .099 & 2.930 & 1.23 & 12.65 \\
\hline \multirow{3}{*}{$\begin{array}{l}\text { Education Level of } \\
\text { the Participant }\end{array}$} & Primary & $61(57.0)$ & $69(58.5)$ & .069 & 6.915 & 2.25 & 14.66 \\
\hline & Secondary & $30(28.0)$ & $24(20.3)$ & .030 & 1.964 & 1.00 & 4.34 \\
\hline & Tertiary & $7(6.5)$ & $6(51.1)$ & .023 & 1.284 & 1.10 & 7.36 \\
\hline
\end{tabular}

\subsubsection{Knowledge and Late ANC Booking}

The logistic regression results in Table 4 indicated a significant association between participants who responded 'Yes' to the need to attend ANC despite any complications $(\mathrm{OR}=7.964,95 \% \mathrm{CI}=2.308-27.486$, p-value $=0.001)$.

Table 4. Logistic regression for Knowledge factors and Early ANC booking.

\begin{tabular}{|c|c|c|c|c|c|c|c|}
\hline \multirow[b]{2}{*}{ Category } & \multirow[b]{2}{*}{ Characteristic } & \multicolumn{2}{|c|}{ Gestation at the First ANC booking } & \multirow[b]{2}{*}{ P-value } & \multirow[b]{2}{*}{ OR } & \multicolumn{2}{|c|}{$95.0 \%$ C.I. for $\operatorname{EXP}(\beta)$} \\
\hline & & $\begin{array}{l}\text { Less than } 14 \\
\text { Weeks }\end{array}$ & $\begin{array}{l}\text { At } 14 \text { Weeks and } \\
\text { Above }\end{array}$ & & & Lower & Upper \\
\hline \multirow{2}{*}{$\begin{array}{l}\text { Do pregnant women need to go for } \\
\text { Antenatal Check Up? }\end{array}$} & Yes & $104(97.2)$ & $118(100)$ & \multirow{2}{*}{.999} & \multirow{2}{*}{0.734} & \multirow{2}{*}{.000} & \multirow{2}{*}{.0} \\
\hline & No & $3(2.8)$ & $0(0)$ & & & & \\
\hline \multirow{2}{*}{$\begin{array}{l}\text { If yes, is ANC required even if there is } \\
\text { no complication during pregnancy? }\end{array}$} & Yes & $101(94.4)$ & $96(81.4)$ & \multirow{2}{*}{.001} & \multirow{2}{*}{7.964} & \multirow{2}{*}{2.308} & \multirow{2}{*}{27.486} \\
\hline & No & $6(5.6)$ & $22(18.6)$ & & & & \\
\hline $\begin{array}{l}\text { Is Early ANC important to pregnant } \\
\text { mother and unborn child? }\end{array}$ & Yes & $107(100)$ & $118(100)$ & .999 & 0.677 & .110 & 12.345 \\
\hline \multirow{2}{*}{$\begin{array}{l}\text { Should first ANC be done in the first } 3 \\
\text { months of the pregnancy? }\end{array}$} & Yes & $107(100)$ & $115(97.5)$ & \multirow{2}{*}{.999} & \multirow{2}{*}{0.544} & \multirow{2}{*}{.264} & \multirow{2}{*}{.6 .23} \\
\hline & No & $0(0)$ & $3(2.5)$ & & & & \\
\hline
\end{tabular}

\subsubsection{Social-Economic Factors and Late ANC Booking}

The binary logistic regression results in Table 5 indicated that there is a significant association between decision making to book for ANC $(\mathrm{OR}=.111$, p-value $=<0.0001,95 \% \mathrm{CI}=.059-.208)$.

Table 5. Logistic regression for Social Economic factors and Early ANC booking.

\begin{tabular}{|c|c|c|c|c|c|c|c|}
\hline \multirow[b]{2}{*}{ Category } & \multirow[b]{2}{*}{ Characteristics } & \multicolumn{2}{|c|}{ Gestation at the First ANC booking } & \multirow[b]{2}{*}{ P-value } & \multirow[b]{2}{*}{ OR } & \multicolumn{2}{|c|}{ 95.0\% C.I. for EXP (B) } \\
\hline & & $\begin{array}{l}\text { Less than } 14 \\
\text { Weeks }\end{array}$ & $\begin{array}{l}\text { At } 14 \text { Weeks and } \\
\text { Above }\end{array}$ & & & Lower & Upper \\
\hline \multirow{2}{*}{$\begin{array}{l}\text { Husband/Partner or family members } \\
\text { makes decision }\end{array}$} & Agree & $33(30.8)$ & $94(79.7)$ & \multirow{2}{*}{.000} & \multirow{2}{*}{.111} & \multirow{2}{*}{.059} & \multirow{2}{*}{.208} \\
\hline & Disagree & $74(69.2)$ & $24(20.3)$ & & & & \\
\hline \multirow{3}{*}{$\begin{array}{l}\text { Monthly House Hold Income of the } \\
\text { Participant }\end{array}$} & Less than K500 & $78(72.9)$ & $100(84.7)$ & .514 & .648 & .233 & .973 \\
\hline & K500-K1000 & $18(16.8)$ & $12(10.2)$ & .971 & .979 & .304 & 3.155 \\
\hline & Above K1000 & $11(10.3)$ & $6(5.1)$ & .444 & .579 & .143 & 2.349 \\
\hline \multirow{2}{*}{$\begin{array}{l}\text { Are you with your spouse able to meet } \\
\text { transport Cost for Antenatal Booking }\end{array}$} & Yes & $101(94.4)$ & $112(94.9)$ & \multirow{2}{*}{.419} & \multirow{2}{*}{.588} & \multirow{2}{*}{.162} & \multirow{2}{*}{2.135} \\
\hline & No & $6(5.6)$ & $6(5.1)$ & & & & \\
\hline
\end{tabular}

\subsubsection{Obstetric Factors and Late ANC Booking}

In Table 6, presents results of obstetric factors and late ANC booking. There was a significant association between participants who had the first pregnancy with early ANC booking ( $p$-value $=0.012$ ). The results further indicated a significant association between participants who had no child and registering a first pregnancy ( $p$-value $=0.024)$. Participants who recognised their pregnancy through missing periods were 0.150 times less likely to report early for ANC. The results, therefore, indicated a significant association between method of pregnancy detection and early ANC (OR=0.68, 95\% $\mathrm{CI}=0.068-0.329, \quad$ p-value $=0.004$, .). Participants with unplanned pregnancy were 2.1 times more likely to book late for $\quad \mathrm{ANC} \quad(\mathrm{OR}=2.13, \quad 95 \% \quad \mathrm{CI}=6.385-71.406$, $\mathrm{p}$-value $=<0.0001)$. 
Table 6. Obstetric factors and Late ANC booking.

\begin{tabular}{|c|c|c|c|c|c|c|c|}
\hline \multirow{2}{*}{ Category } & \multirow{2}{*}{ Characteristic } & \multicolumn{2}{|c|}{$\begin{array}{l}\text { Gestation at the First ANC } \\
\text { booking }\end{array}$} & \multirow{2}{*}{ P-value } & \multirow{2}{*}{ OR } & \multicolumn{2}{|c|}{$\begin{array}{l}\text { 95\% Confidence } \\
\text { Interval }\end{array}$} \\
\hline & & $\begin{array}{l}\text { Less than } 14 \\
\text { Weeks }\end{array}$ & $\begin{array}{l}\text { At } 14 \text { Weeks } \\
\text { and Above }\end{array}$ & & & Lower & Upper \\
\hline \multirow{4}{*}{$\begin{array}{l}\text { Number of pregnancies a } \\
\text { participant have had? }\end{array}$} & 1st Pregnancy & $47(43.9)$ & $21(17.8)$ & .012 & 1.47 & .02 & \multirow{4}{*}{4.23} \\
\hline & 2-4 Pregnancies & $60(56.1)$ & 49 (41.5) & .997 & .000 & .000 & \\
\hline & 5 and Above pregnancies & $0(0)$ & $48(40.7)$ & .997 & .000 & .000 & \\
\hline & Zero & $47(43.9)$ & $21(17.8)$ & .024 & 1.65 & .56 & \\
\hline \multirow{3}{*}{$\begin{array}{l}\text { Number of Children a participant } \\
\text { have? }\end{array}$} & 1-2 Children & $54(50.50$ & $31(26.3)$ & .999 & .000 & .000 & \multirow{3}{*}{5.23} \\
\hline & 3-4 Children & $6(5.6)$ & $57(48.3)$ & .999 & .000 & .000 & \\
\hline & 5 Children and Above & $0(0)$ & $9(7.6)$ & .999 & .000 & .000 & \\
\hline $\begin{array}{l}\text { How the participant recognised } \\
\text { they were pregnant? }\end{array}$ & $\begin{array}{l}\text { Missing periods } \\
\text { Urine sticks }\end{array}$ & $\begin{array}{l}69(64.5) \\
38(35.5)\end{array}$ & $\begin{array}{l}109(92.4) \\
9(7.6)\end{array}$ & .004 & .150 & .068 & .329 \\
\hline Planned pregnancy & $\begin{array}{l}\text { Yes } \\
\text { No }\end{array}$ & $\begin{array}{l}104(97.2) \\
3(2.8)\end{array}$ & $\begin{array}{l}73(61.9) \\
45(38.1)\end{array}$ & .000 & 2.137 & 6.385 & 71.406 \\
\hline
\end{tabular}

\subsubsection{Access to Health Care Services and Late ANC Booking}

The results in Table 7 indicate that there was a significant association between duration to reach the ANC providing centre with early ANC booking ( $\mathrm{OR}=0.207,95 \% \mathrm{CI}: .057-.751$, $\mathrm{p}$-value $=0.017$ ). The binary logistic regression results further indicated that there is a significant relationship between travel means to access ANC services and Early ANC booking. Walking as a means to access the ANC providing centre was not associated with early ANC booking $(\mathrm{OR}=1, \mathrm{p}$-value $=0.033)$.

Logistic regression for accessibility to health care services and late ANC booking

Table 7. Health Care Services and Late ANC booking.

\begin{tabular}{llllllll}
\hline \multirow{2}{*}{ Category } & Characteristics & \multicolumn{2}{l}{ Gestation at the 1st ANC booking? } & & \multicolumn{2}{c}{ 95.0\% C.I. for EXP( $\boldsymbol{\beta})$} \\
\cline { 3 - 4 } & & $\begin{array}{l}\text { Less than 14 } \\
\text { Weeks }\end{array}$ & $\begin{array}{l}\text { At 14 Weeks and } \\
\text { Above }\end{array}$ & P-value & OR & Lower & Upper \\
\hline How long does it takes for the & Less than 30 Minutes & $59(55.1)$ & $27(22.9)$ & .000 & .051 & .011 \\
participant to reach the ANC & 30 Minutes to 1 Hour & $45(42.1)$ & $70(59.2)$ & .000 & .050 & .013 & .991 \\
providing centre. & More than 1 Hour & $3(2.8)$ & $2(17.8)$ & .017 & .207 & .057 & .191 \\
Travel Means to access ANC & Walking & $80(74.8)$ & $91(77.1)$ & .033 & .061 & .012 & .751 \\
services by the Participant & Bicycle & $27(25.2)$ & $21(17.8)$ & .999 & .000 & .000 & .873 \\
& Motor Bike & $0(0)$ & $6(5.1)$ & .999 & .000 & .000 & .000 \\
\hline
\end{tabular}

\subsubsection{Health Systems Related Factors and Early ANC Booking}

The test results in Table 8 indicated that there is a significant association between staff attitude and early ANC booking $(\mathrm{OR}=1.973,95 \% \mathrm{CI}=1.730-2.249$, $\mathrm{p}$-value $=0.006)$. There is a further significant association between participants affected by staff attitude and early ANC booking ( $\mathrm{OR}=1.939$, $95 \% \mathrm{CI}=1.706-2.203$, $\mathrm{p}$-value $=0.045$ ).

Table 8. Logistic regression for Health Services Related Factors and Early ANC booking.

\begin{tabular}{|c|c|c|c|c|c|c|c|}
\hline \multirow{2}{*}{ Category } & \multirow{2}{*}{ Characteristic } & \multicolumn{2}{|c|}{$\begin{array}{l}\text { Gestation at the 1st ANC } \\
\text { booking? }\end{array}$} & \multirow{2}{*}{ P-value } & \multirow{2}{*}{ OR } & \multicolumn{2}{|c|}{$\begin{array}{l}\text { 95\% Confidence } \\
\text { Interval } \\
\end{array}$} \\
\hline & & $\begin{array}{l}\text { Less than } 14 \\
\text { Weeks }\end{array}$ & $\begin{array}{l}\text { At } 14 \text { Weeks } \\
\text { and Above }\end{array}$ & & & Lower & Upper \\
\hline How is the attitude of the staff at the & $\mathrm{Bad}$ & $0(0)$ & $8(6.8)$ & .006 & 1.973 & 1.730 & 2.249 \\
\hline ANC providing centre? & Good & $107(100)$ & $110(93.2)$ & 0.638 & 1.065 & 1.001 & 2.034 \\
\hline Does staff attitude affect your early & Yes & $0(0)$ & $4(3.4)$ & .045 & 1.939 & 1.706 & 2.203 \\
\hline ANC booking decision? & No & $107(100 \%)$ & $114(96.6)$ & .464 & 1.103 & 0.997 & 2.312 \\
\hline Is antenatal care provided in any of the & Yes & $104(97.2)$ & $118(100)$ & .067 & .468 & .407 & .539 \\
\hline working days of the week? & No & $3(2.8)$ & $0(0)$ & .999 & .000 & .000 & .000 \\
\hline How long the participant wait at the & Less than 30 Minutes & $30(28.0)$ & $36(30.5)$ & .684 & .887 & .499 & 1.578 \\
\hline $\begin{array}{l}\text { ANC providing centre to receive a } \\
\text { service? }\end{array}$ & 30 Minutes and more & $77(72.0)$ & $82(69.5)$ & .678 & 1.125 & .646 & 1.956 \\
\hline Does waiting time negatively affect & Yes & $15(14.0)$ & $19(16.6)$ & .663 & .850 & .408 & 1.770 \\
\hline $\begin{array}{l}\text { the decision of the participant for } \\
\text { booking early for ANC) }\end{array}$ & No & $92(86.0)$ & $89(83.9)$ & .613 & 1.177 & .565 & 2.453 \\
\hline
\end{tabular}

\subsubsection{Other Determinants of Late ANC Booking}

Figure 3 illustrates other determinants of late ANC booking.
The other reasons were descriptively indicated by the 118 participants who booked late for ANC are given in figure 3. These are: waiting for authorisation from the family or spouse, 
uncertain about the pregnancy, spouse or husband refusal for first early ANC booking, in apparent good health and feeling lazy by the participant. Majority of the participants $27(12 \%)$ of the participants who booked at or after 14 weeks linked their late ANC booking to waiting for authorisation from the family or spouse. For delayed booking, 22 (9.8\%) participants indicated that they delayed booking for ANC since they were in apparent good condition. Hence, they did not see the need to begin ANC early. For delayed ANC booking due to feeling lazy, $21(9.3 \%)$ participants attributed the delay to this while $18(8.0 \%)$ participants indicated that their late ANC booking was a result of spouse refusal to escort them for first ANC booking.

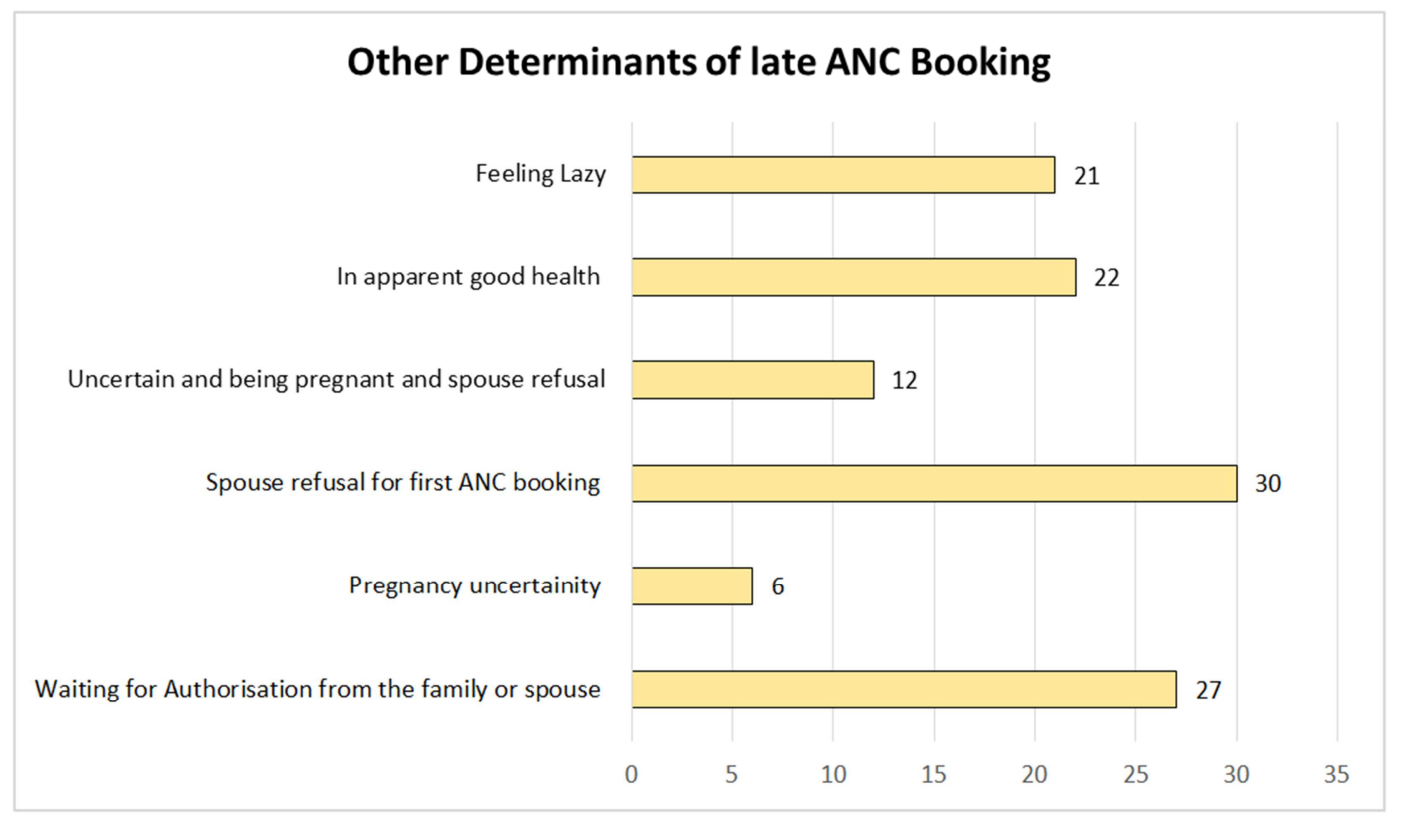

Figure 3. Other Determinants of Late ANC Booking.

\section{Discussion}

\subsection{Women's Factors and Late ANC Booking}

From the study, a total number 107 (47.6\%) of the participants booked before 14 weeks and the rest booked at and after 14 weeks of gestations. The late ANC booking was lower than the HMIS record for 2018 [10].

Logistic regression results indicated a significant association between the maternal age of the participants and ANC booking $(\mathrm{OR}=1.7$, $\mathrm{p}$-value $=<0.0001$,$) . Maternal age$ category 15-25 years of age was, therefore, 1.7 times more likely to book early for ANC than the other age categories. The findings of the study further indicated a significant association between maternal marital status and early ANC booking (OR=7.6, 95\% CI: 2.801-21.020, p-value $=<0.0001)$. Single maternal participants were 7.6 times more likely to book early for ANC. This finding is supported by the study done in Zambia by [15].

Binary logistic regression analysis results further indicated a significant association between early ANC booking and maternal education as follows: Secondary school $(\mathrm{OR}=6.9$, $\mathrm{p}$-value $=0.030)$ and Tertiary $(\mathrm{OR}=1.964, \mathrm{p}$-value $=0.023)$. Women who had reached higher education level of were more likely to book early for ANC. The finding is supported by different studies which include those by $[14,28]$ in Ethiopia [9]. Research results further indicated that the higher the education level of the woman, the less likely the chances of booking late for ANC. This is in conformity with the research results by [18] who found that relatively affluent women with a high level of education were more likely to attend at ANC than others.

Results indicated a significant association between participants who responded 'Yes' to the need to attend ANC despite any complications ( $\mathrm{OR}=7.964,95 \% \mathrm{CI}$ : 2.308-27.486, p-value $=0.001)$. This indicates that participants who understood that early ANC booking is important despite any noticeable complication during pregnancy were 7.96 times more likely to book early for ANC. Findings of the research are supported by the research conducted in Nigeria by [21].

\subsection{Societal and Traditional Factors with Late ANC Booking}

The study revealed a significant association between decision making to book for ANC and early ANC booking $(\mathrm{OR}=.111,95 \% \mathrm{CI}$ : 059-.208, p-value=.000,). Findings of the study are, therefore, supported the research conducted by [29]. The study indicated that there is a significant association between maternal gravida with late ANC booking. Women with the first pregnancy were 1.5 times more likely to book early for $\mathrm{ANC}$ than others $(\mathrm{OR}=1.47$, $\mathrm{p}$-value=0.012). The regression results further indicated a significant association between parity of the woman and early ANC booking. Participants who had no child were 1.7 times more likely to 
book early for ANC than those who had children (OR=1.65, $\mathrm{p}$-value $=0.024)$. A study conducted in Tanzania revealed a significant association between parity and early ANC booking [23]. Similarly in Ghana, higher parity women were less likely to book for antenatal [24]. This is also confirmed from the study in Benin by [18].

Participants who recognised their pregnancy through missing periods were 0.150 times less likely to report early for ANC. The test results, therefore, indicated a significant association between method of pregnancy detection and early ANC ( $\mathrm{OR}=0.68,95 \% \mathrm{CI}=0.068-0.329$, $\mathrm{p}$-value $=0.004)$. This finding is supported by other different studies that have indicated a significant association between pregnancy uncertainty and early ANC booking. In Ghana, pregnancy uncertainty was highly associated with early ANC booking [24].

Participants with unplanned pregnancy were 2.1 times more likely to book late for $\mathrm{ANC}(\mathrm{OR}=2.1,95 \% \mathrm{CI}=6.385-71.406$, $\mathrm{p}$-value $=<0.0001)$. The findings are supported by other studies within and outside Zambia. For example, study by [6] indicated that unwanted pregnancy is a significant factor affecting early ANC booking. Furthermore, research by [9] indicated that women with unwanted pregnancy were more likely to book late for ANC.

\subsection{Health System Factors and Late ANC Booking}

Findings of the study indicated that there was a significant association between duration to reach the ANC providing centre with early ANC booking $(\mathrm{OR}=0.207$, p-value $=0.017)$. Therefore, women who took 1 hour and more were 0.207 times more likely to book late for ANC. Binary logistic regression results further indicated that there was significant relationship between travel means to access ANC services and early ANC booking. Among different transport methods used to access health care, walking to the ANC providing centre was associated with early ANC booking $(\mathrm{OR}=1$, $\mathrm{p}$-value $=0.033$ ). Clients who walked to access the ANC providing services were, therefore, more likely to book early for ANC. In Cameroon, distance was a significant factor to early ANC booking [30]. The results indicated that there was a significant association between staff attitude and early ANC booking $\quad(\mathrm{OR}=1.973, \quad 95 \% \quad \mathrm{CI}=1.730-2.249$, $\mathrm{p}$-value $=0.006)$.

Other reasons indicated by the 118 participants who booked late for ANC were waiting for authorisation from the family or spouse, uncertain about the pregnancy, spouse or husband refusal for first early ANC booking, in apparent good health and feeling lazy by the participant. These factors are supported by the findings of other researches which were done in different countries. In Tanzania early ANC booking was associated with partner's support. Therefore, women who were supported by partners during pregnancy were likely to book for ANC earlier [23]. Furthermore, [29] indicates that women with spouses who approved ANC were more likely to book early for ANC. Findings of the research are supported by research study done by [13] in Ethiopia which revealed that other determinants of late ANC booking include feeling of laziness by pregnant women and feeling of good health.

\subsection{Limitations}

Data collected were based on self-reports from the study participants. This might have created a problem of recall bias.

\section{Conclusion}

The determinants of late first ANC booking in Kasenengwa district are maternal age, maternal marital status, maternal education, and knowledge on need to begin ANC within the first 14 weeks despite any noticeable pregnancy complications, maternal gravida/parity, and method of pregnancy detection and planned pregnancy. Societal/traditional factors that were significantly associated with late ANC booking were duration to reach the ANC providing centre and travel means to access ANC services. The study found that staff attitude is a health system determinant significantly associated with late ANC booking. Other determinants of late ANC booking were authorisation from the family or spouse to begin ANC, pregnancy uncertainty, spouse or husband refusal for first early ANC booking, in apparent good health and feeling lazy.

\section{Recommendations}

\subsection{National Level}

i. Development of deliberate policies that support free education to women in order to improve maternal education.

ii. Support the District level with continuous availability of pregnancy test logistics to improve pregnancy detection.

iii.Deliberately development of the toll free central line for the reporting of poor staff attitude during ANC services provision.

\subsection{District Level}

i. Traditional leaders' engagement to bring on board the realization for importance of early ANC booking amongst male.

ii. Development of Health Education messages to be shared with the health facilities with emphasis to begin Antenatal early despite any noticeable pregnancy complications.

iii. Support the health facilities with continuous availability of pregnancy test logistics to improve pregnancy detection among women.

iv. Support the Health facilities to establish primary health care structures in the outreach posts to improve access to health care.

v. Enforcement of punitive disciplinary measures against bad attitude report during ANC services provision.

\subsection{Health Facility Level}

i. Embedment of health education messages on importance of early ANC booking in all gatherings with 
Women of Child Bearing Age.

ii. Focus health education messages on importance of early ANC booking during pregnancy despite any noticeable pregnancy complication.

iii. Embedment of health education messages on partners support in all gatherings with adult males.

iv. Develop a deliberate program where multpality women who book early for ANC are provided with ANC services before the others.

v. Provision of free pregnancy testing kits to the community based volunteers to improve pregnancy detection in the community.

vi. Integration of ANC services provision during growth monitoring in all the outreach points.

vii. Development of complaint desk under mother child health department to improve customer care.

\section{Declarations}

\section{Conflict of Interest}

The authors declare that they have no competing interests.

\section{Author Contributions}

SMW conceptualised and designed, analysed and interpreted the data; drafted article and approved the final version of the article. GL designed the study, revised the article critically for important intellectual content; and approved the version to be published. EK reviewed the design, analysed and interpreted the data, drafted the article and approved the final version of the article. All the authors approved the final manuscript.

\section{Acknowledgements}

We would like to express our sincere appreciation to the Kasenengwa District Health Management team for providing us with the needed information for the research.

\section{References}

[1] World Health Organisation (WHO) (2016). WHO recommendations on antenatal care for a positive pregnancy experience. World Health Organisation. Accessed on the $26^{\text {th }}$ July

http://apps.who.int/iris/bitstream/handle/10665/250796/97892 415499 12-eng.pdf?

[2] Lancetto O, Mothebesoane-Anoh S, Gomez P, Munjanja S (2010). Antenatal Care: Opportunities for Africa's Newborns. New York: World Health Organisation. Accessed on $14^{\text {th }}$ July 2019 at https://www.who.int/pmnch/media/publications/aonsectionIII_2.p df.

[3] Onoh, R., Umerora, O., Agwu, U., Ezegwui, H., Ezeonu, P., \& Onyebuchi, A. (2012). Pattern and determinants of antenatal booking at abakaliki southeast Nigeria. Annals of medical and health sciences research. Accessed on $11^{\text {th }}$ August at https://www.ncbi.nlm.nih.gov/pubmed/?term=Onoh\%20R\%5 BAuthor\%5D\&cauthor=true\&cauthor uid $=23439716$.
[4] Wildman K, Blondel B, Nijhuis J, Defoort P, Bakoula C. European indicators of health care during pregnancy, delivery and the postpartum period. European Journal of Obstetrics \& Gynecology and Reproductive Biology. 111: S53-S65. Accessed on the 14 November, 2019 on https://biblio.ugent.be/publication/288759.

[5] Lawn JE, Lee AC, Kinney M, Sibley L, Carlo WA, Paul VK, et al (2009). Two million intrapartum-related stillbirths and neonatal deaths: Where, why, and what can be done? International Journal for Gynecology Obstet. Accessed on the $15^{\text {th }}$ November, 2020 on https://www.ncbi.nlm.nih.gov/pmc/articles/PMC3977142/.

[6] Banda I, Michelo C, Hazemba A. Factors associated with late antenatal care attendance in selected rural and urban communities of the Copperbelt province of Zambia: Medical Journal of Zambia. Accessed on $14^{\text {th }}$ July 2019 at https://www.ajol.info/index.php/mjz/article/view/110594.

[7] Wang W, Alva S, Wang S et al., (2011) Levels and Trends in the Use of Maternal Health Services in Developing Countries. DHS Comparative Reports N0 26. Calverton, Maryland, USA: ICF Macro. Accessed on $14^{\text {th }}$ December, 2019 on https://hsprogram.com/pubs/pdf/CR26/CR26.pdf.

[8] Zambia Statistics Agency, Ministry of Health (MOH) Zambia, and ICF. 2019. Zambia Demographic and Health Survey 2018. Lusaka, Zambia, and Rockville, Maryland, USA: Zambia Statistics Agency, Ministry of Health, and ICF.

[9] Nyambe S, Lungowe S, Choolwe J et al., (2018). Factors associated with late antenatal care booking: population based observations from the 2007 Zambia demographic and health survey. Pan African Medical Journal. Accessed on $14^{\text {th }}$ July 2019 at https://www.researchgate.net/publication/309433924.

[10] Health Management Information System (HMIS) (2018). Ministry of Health.

[11] Gebrekidan K, Worku A (2017). Factors associated with late ANC initiation among pregnant women in select public health centers of Addis Ababa, Ethiopia: unmatched case-control study design: Dove press. Accessed on the 15 November, 2019 at https://pubmed.ncbi.nlm.nih.gov/29138615/.

[12] Ethiopia Demographic and Health Survey (EDHS, 2011). Available from: on https://dhsprogram.com/pubs/pdf/fr255/fr255.pdf. Accessed on $11^{\text {th }}$ July 2019.

[13] Temesgen W G, Solomon M W and Abdella A A (2014). Timing and factors associated with first antenatal care booking among pregnant mothers in Gondar Town; North West Ethiopia: BMC Pregnancy and Childbirth. Accessed on the https://bmcpregnancychildbirth.biomedcentral.com/articles/10 .1186/1471-2393-14-287.

[14] Gebrekidan K, Worku A. Factors associated with late ANC initiation among pregnant women in select public health centers of Addis Ababa, Ethiopia: unmatched case-control study design. Pragmatic and observational research. 2017; 8: 223. doi: 10.2147/POR.S140733.

[15] Chewe M M, Mutinta M C and Maimbolwa M (2017). Factors associated with late antenatal care booking among pregnant women in Ndola district, Copperbelt Province, Zambia. Midwifery and Women's Health. https://www.longdom.org/proceedings/factors-associated-with -late-antenatal-care-booking-among-pregnant-women-in-ndol a-district-copperbelt-province-zambia-in-37876.html. Accessed on $16^{\text {th }}$ July, 2019. 
[16] Hatherall B, Morris J, Jamal F, Sweeney L, Wiggins M, Kaur I, Renton A, Harden A. Timing of the initiation of antenatal care: An exploratory qualitative study of women and service providers in East London. Midwifery. Accessed on $12^{\text {th }}$ November, 2020 https://pubmed.ncbi.nlm.nih.gov/27106937/.

[17] Zhao Q, Huang ZJ, Yang S, et al. The utilisation of antenatal care among rural-to-urban migrant women in Shanghai: a hospital-based cross-sectional study. BMC Public Health. Accessed on the $17^{\text {th }}$ October, 2020 on https://bmcpublichealth.biomedcentral.com/articles/10.1186/1 471-2458-12-1012.

[18] Agonnoude Togbedji Maurice, Assogba Abdul Koudous, Ahouignan-Hounkponou Fanny, Houeto Segbegnon David, Sossa Jerome Charles, Zannou Gbenoukpo Sebastien. Social Status as Predictor of Pregnant Women Attendance at Antenatal Care. Central African Journal of Public Health. Vol. 7, No. 1, 2021, pp. 40-46. doi: 10.11648/j.cajph.20210701.15.

[19] Midhet F, Becker S, Berendes HW. Contextual determinants of maternal mortality in rural Pakistan. Soc Sci Med. 1998; 46: 1587-98. Accessed on the $14^{\text {th }}$ November, 2029 on https://pubmed.ncbi.nlm.nih.gov/9672397/.

[20] Birmeta K, Dibaba Y, Woldeyohannes D. Determinants of maternal health care utilization in Holeta town, central Ethiopia BMC Health Serv Res. 2013; 13: 1. Accessed on the $19^{\text {th }}$ October, 2019 on https://pubmed.ncbi.nlm.nih.gov/23822155/.

[21] Onasosoga, Olayinka A, Afolayan, J A et al (2012). Factors influencing utilisation of antenatal care services among pregnant women in Ife Central Lga, Osun State Nigeria: Pelagia Research Library. Accessed on the $13^{\text {th }}$ July, 2020 on https://www.imedpub.com/articles/factors-influencing-utilizati on-of-antenatal-care-services-among-pregnantwomen-in-ife-c entral-lga-osun-state-nigeria.pdf.

[22] Sakeah E, Okawa S, Rexford Oduro A, et al. Determinants of attending antenatal care at least four times in rural Ghana: analysis of a cross-sectional survey. Glob Health Action. 2017;
10 (1): 1291879. doi: 10.1080/16549716.2017.1291879. Accessed on the $20^{\text {th }}$ October, 2020 on https://www.ncbi.nlm.nih.gov/pmc/articles/PMC5496066/.

[23] Gross, K., Alba, S., Glass, T.R. et al. Timing of antenatal care for adolescent and adult pregnant women in south-eastern Tanzania. BMC Pregnancy Childbirth 12, 16 (2012). https://doi.org/10.1186/1471-2393-12-16.

[24] Kaswa R, Rupesinghe GFD, Longo-Mbenza B. Exploring the pregnant women's perspective of late booking of antenatal care services at Mbekweni Health Centre in Eastern Cape, South Africa. Afr J Prm Health Care Fam Med. 2018; 10 (1), a1300. Accessed on the $9^{\text {th }}$ July 2019 at https://doi.org/10.4102/phcfm.v10i1.1300.

[25] Andersen RM, Newman JF. Societal and individual determinants of medical care utilisation in the United States. Milbank Memorial Fund Quarterly- Health and Society 1973; 51 (1). Accessed on the $29^{\text {th }}$ July, 2019 at http://umanitoba.ca/faculties/health_sciences/medicine/units/c hs/departmental units/mchp/protocol/media/Andersen_and N ewman_Framework.pdf.

[26] Yamane T. (1967) Statistics an Introductory Analysis. 2nd Edition, New York, Harper and Row.

[27] Yaya S, Bishwajit G, Ekholuenetale M, Shah V, Kadio B, Udenigwe $O$ (2017) Timing and adequate attendance of antenatal care visits among women in Ethiopia. PLoS ONE 12 (9): e0184934. https://doi.org/10.1371/journal.pone.0184934.

[28] Rosliza A M, Muhamad H J (2011). Attitude and Practice on Antenatal Care among women: Jempol. Malaysian Journal of Public Health Medicine. Accessed on $14^{\text {th }}$ July 2019 at https://www.mjphm.org.my/mjphm/journals/Volume\%2011:2/ 188.

[29] Tolefac, P. N., Halle-Ekane, G. E., Agbor, V. N. et al. Why do pregnant women present late for their first antenatal care consultation in Cameroon?. matern health, neonatol and perinatol 3, 29 (2017). Accessed on $12^{\text {th }}$ October, 2019 at https://doi.org/10.1186/s40748-017-0067-8. 